\title{
Los sistemas naturales españoles
}

\author{
Juan Carlos Simón Zarzoso'
}

Sumario: I. INTRODUCCIÓN. II. RIQUEZA FLORÍSTICA. III. LOS SISTEMAS NATURALES ESPAÑOLES. 1. El medio terrestre. 2. El medio acuático continental. 3. El medio costero y marino. IV. BIBLIOGRAFÍA.

\section{INTRODUCCIÓN}

El Convenio sobre la Diversidad Biológica (CBD, 1992) define la biodiversidad como la "variabilidad de organismos vivos de cualquier fuente, incluidos, entre otras cosas, los ecosistemas terrestres y marinos y otros ecosistemas acuáticos, y los complejos ecológicos de los que forman parte; incluye la diversidad dentro de cada especie, entre las especies y de los ecosistemas". Por consiguiente, la variedad de la vida comprende varios niveles como son el de la diversidad genética, el de la diversidad de especies (cada una de ellas con sus poblaciones) o el nivel de diversidad de comunidades (biocenosis) y ecosistemas ${ }^{2}$. En este artículo se trata la diversidad biológica a escala de ecosistema, es decir, el nivel que describe el conjunto de especies que pueden encontrarse en un territorio dado, sus relaciones entre sí y sus relaciones con el ambiente en el que se desarrollan. De esta forma, podemos considerar que los ecosistemas y la biodiversidad de un área dependen de tres atributos fundamentales organizados de forma jerárquica: la composición, la estructura y la función (Noss, 1990).

Si bien el concepto de especie supone una unidad de referencia de biodiversidad más o menos establecida, no ocurre lo mismo con el concepto de ecosistema. El conjunto de especies (con sus poblaciones diferentes) presentes en un territorio como España, sus relaciones más o menos intensas y sus distintos grados de adaptación al medio conforman una diversidad de comunidades y ecosistemas que difícilmente

1 Consultor. Coordinador del proyecto "Bases ecológicas preliminares para la conservación de los tipos de interés comunitario en España".

2 Las fitocenosis (comunidades vegetales), junto con los microorganismos y las comunidades animales forman comunidades de organismos (biocenosis) más o menos amplias, las cuales, a su vez, se integran con el ambiente correspondiente en biogeocenosis. (Strasburguer, 1986). 
puede caracterizarse. Esta complejidad es mucho mayor aún si se consideran las actividades humanas que durante milenios han modificado profundamente el paisaje. De hecho, hay no pocas propuestas de clasificación del territorio y de los sistemas naturales o seminaturales presentes en España, pero no hay una tipología claramente admitida o consensuada que sirva de referencia, la cual, en cierta medida, también depende de la utilidad para la que pueda ser concebida. No hay que olvidar tampoco los inconvenientes conceptuales asociados a un proceso de clasificación. Los sistemas naturales son tan complejos que si medimos muchas variables bióticas y abióticas podemos concluir que no hay dos enclaves o zonas iguales y, por consiguiente, no es posible una clasificación. Es preciso entonces adoptar un enfoque intermedio que permita encontrar ciertas similitudes en el espacio, lo cual conlleva una ordenación de la información y un principio de clasificación o de tipología. Si somos capaces de definir tipos de ecosistemas podemos representarlos (cartografía) y podemos abordar su caracterización mediante una serie de atributos más o menos objetivos como son la originalidad, la integridad, la complejidad, la biodiversidad, la exclusividad, la rareza o incluso la presión o la amenaza de desaparición.

En cualquier caso, para entender el componente biológico y el componente abiótico de los sistemas naturales de un territorio hay que considerar los procesos evolutivos y ambientales acontecidos a lo largo de la historia geológica y, desde luego, nuestra propia historia. No es objeto de este artículo hacer una visión cronológica resumida de la historia natural de España sino explicar brevemente en qué consiste la diversidad actual de sistemas naturales ${ }^{3}$ que podemos encontrar, cuáles son los principales problemas a los que se enfrentan y qué medidas o estrategias generales de conservación están actualmente en marcha. Las conclusiones de "La Evaluación de los Ecosistemas del Milenio" (2005) señalan que "En los últimos 50 años, los seres humanos han transformado los ecosistemas más rápida y extensamente que en ningún otro período de tiempo de la historia humana con el que se pueda comparar, en gran medida para resolver rápidamente las demandas crecientes de alimentos, agua dulce, madera, fibra y combustible. Esta transformación del planeta ha aportado considerables beneficios netos para el bienestar humano y el desarrollo económico. Pero no todas las regiones ni todos los grupos de personas se han beneficiado de este proceso -de hecho, a muchos les ha perjudicado. Además, sólo ahora se están poniendo de manifiesto los verdaderos costos asociados con esos beneficios."

El sistema de desarrollo o metabolismo socio-económico de los países más ricos se basa, desde luego, en un uso creciente de los recursos materiales y de la energía, que suele traducirse en términos simplistas en un crecimiento económico ininterrumpido (PIB). España no es en absoluto ajena a esta fuerza directriz de crecimiento económico. De hecho, hay datos claros que muestran el espectacular incremento del consumo de todo tipo de recursos naturales (servicios de los ecosistemas) desde la

3 En ningún momento debe pensarse que en el territorio español existen sistemas naturales en el sentido de que apenas han sido modificados por la actividad humana. Nos referimos con el término "natural" al territorio no urbano ni ocupado por granes zonas de cultivo intensivo. 
década de los sesenta, incuso a tasas superiores a las del resto de los países ricos (proceso de terciarización). El resultado de este proceso ha sido la polarización-segregación del territorio en áreas donde se concentra la población y las actividades frente a zonas aquejadas de despoblamiento y abandono, con el deterioro simultáneo de ambas (Parra y Naredo, 2002; Carpintero, 2005; Naredo, 2006). El proceso de concentración de la población en el litoral (litoralización), sobre todo mediterráneo, es un ejemplo extremo de este principio.

Las medidas o estrategias generales en materia de conservación de la diversidad biológica y del patrimonio geológico se basan en aplicar con efectividad la nueva Ley 42/2007 de Patrimonio Natural y de la biodiversidad. Ello implica cuestiones globales como son redactar el Plan Estratégico Estatal, las directrices de Ordenación de los Recursos Naturales y, especialmente, redactar los Planes sectoriales ya que son las políticas y actividades sectoriales las que verdaderamente planifican y controlan el medio ambiente. Cuestiones relevantes más específicas que plantea dicha ley son las necesidades de seguimiento y evaluación de las especies y de los ecosistemas así como la creación del Catálogo de Hábitats en Peligro de Desaparición, lo que implicará que para dichos hábitats las CCAA deberán definir medidas para frenar o eliminar el riesgo de desaparición. Además, la Conferencia Sectorial de Medio Ambiente deberá aprobar las Estrategias y Planes de conservación y restauración.

Precisamente dos elementos en materia de conservación de la biodiversidad deben considerarse, en el ámbito europeo, como hitos en el avance de trabajos destinados a la clasificación de comunidades y sistemas naturales: el Proyecto Biotopos del Programa europeo Corine 4 y la Directiva 92/43/CEE, relativa a la conservación de los hábitats naturales y de la fauna y flora silvestres.

El Proyecto Biotopos surgió a mediados de los ochenta del siglo pasado (19851990) con el objetivo de seleccionar y caracterizar sitios de importancia comunitaria para la conservación de la naturaleza. Uno de los criterios para la selección de biotopos fue la presencia significativa de tipos de hábitats, por lo que se desarrolló una clasificación jerárquica estructurada en 7 grandes grupos: comunidades costeras y halofíticas, aguas no marinas, matorrales y pastizales, bosques, áreas pantanosas y turberas, hábitats rocosos y, por último, zonas agrarias y paisajes muy artificiales. La primera clasificación comprendía casi 800 tipos y la revisión de 1991 supuso la definición de unos 2.500 tipos de hábitats. El concepto de hábitat implica comunidades biológicas en el sentido de sistemas formados por la flora y la fauna en respuesta al ambiente abiótico y a las mutuas influencias entre sus componentes. El Manual Biotopos Corine define el hábitat como un área de tierra firme o una masa de agua que constituye una unidad ecológica de importancia para la Comunidad con vistas a la

4 http://www.eea.europa.eu/publications/CORo-biotopes 
protección de la naturaleza. Reconoce tres grupos de hábitats: a) naturales o casi naturales (formas originarias de los ecosistemas europeos), b) seminaturales (resultado de una larga historia de explotación del territorio) y c) artificializados (más de tres cuartas partes de la UE). El Departamento de Medio Ambiente y Vivienda de la Generalitat de Cataluña empezó en 2005 a elaborar su manual de hábitats ${ }^{5}$ tomando como referencia el Manual Biotopos Corine. Posteriormente al Manual Biotopos se generó la Clasificación de hábitats del Paleártico (Devillers \& Devillers, 1996) y la incluida en el Sistema EUNIS (European Nature Information System) ${ }^{6}$. Cuando surgió el Proyecto Biotopos, en España estaba bastante avanzada una clasificación de comunidades vegetales basada en la fitosociología, una disciplina que estudia las biocenosis desde la perspectiva botánica (fitocenosis), mediante un método inductivo y estadístico basado en el inventario de vegetación?

La Directiva 92/43/CEE ha supuesto un hito muy importante puesto que incorpora como pilar fundamental para la conservación de la biodiversidad europea un listado de tipos de Hábitats de Interés Comunitario (HIC), recogido en el Anexo I (tabla 1). Este listado representa básicamente un subconjunto más o menos reducido de tipos de hábitats procedente de la clasificación de hábitats del Proyecto Biotopos. Esta directiva define un hábitat natural como una zona terrestre o acuática diferenciada por sus características geográficas, abióticas y bióticas, tanto si son enteramente naturales como seminaturales. Los tipos de hábitats naturales de interés comunitario se definen como aquellos que: a) se encuentran amenazados de desaparición en su área de distribución natural, b) presentan un área reducida a causa de su regresión o por ser un área intrínsecamente reducida y c) constituyen ejemplos representativos de características típicas de una o de varias de las regiones biogeográficas existentes en la Unión Europea. El objetivo básico de esta Directiva es mantener (o restaurar) dichos tipos de HIC (y las especies de interés comunitario) en un estado de conservación favorable.

La aplicación en España de la Directiva Hábitats (Orella et al., 1998) supuso, entre otras cosas, que el Ministerio de Medio Ambiente pusiera en marcha a mediados de la década de los 90 del pasado siglo el primer Inventario Nacional de Hábitats, lo que implicó realizar una cartografía a escala 1:50.000 de las comunidades vegetales reconocibles como tipos de HIC. No obstante, trabajar en la caracterización, delimitación y evaluación de los tipos de HIC lleva asociado tres problemas básicos: la definición, imprecisa en muchos casos; la representación de diferentes niveles de organización (escalas) y la dinámica de cambio de los ecosistemas.

Con respecto a la primera cuestión, los sucesivos manuales de los tipos de HIC realizados por la Comisión Europea contienen definiciones muy breves de los hábi-

5 http://mediambient.gencat.cat/cat/el_medi/habitats/habitats_documents.htm\#mhc

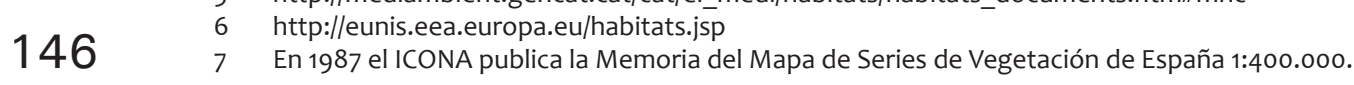


tats, lo que complica su identificación (interpretación) en el territorio. En cuanto a los niveles de organización, el listado de tipos de HIC incluye hábitats que representan grandes unidades territoriales (como son las dehesas, los estuarios o las grandes calas y bahías), y hábitats de reducida extensión (como las praderas marinas de Posidonia oceanica, algunos tipos de pastizales o varios tipos de turberas), que quedan englobados en el funcionamiento de otros sistemas más amplios. En cuanto a la dinámica de cambio, hay que tener en cuenta los procesos más o menos intensos a los que están sometidos los sistemas naturales, los cuales pueden verse muy amplificados por el uso o el desuso de determinadas actividades antrópicas. De esta forma, muchos tipos de HIC, para que se mantengan en un estado de conservación favorable, requerirán medidas activas intensas para frenar o mitigar los procesos de sucesión (cambios en el proceso de organización de las comunidades) que ocurren y que podrían suponer el paso a otros tipos de hábitats.

TABLA 1

Tipos de Hábitats de Interés Comunitario presentes en España

\begin{tabular}{|c|c|}
\hline $\begin{array}{l}1110 \text { Bancos de arena cubiertos } \\
\text { permanentemente por agua marina, poco } \\
\text { profunda }\end{array}$ & $\begin{array}{l}5330 \text { Matorrales termomediterráneos y pre- } \\
\text { estépicos }\end{array}$ \\
\hline $\begin{array}{l}1120 \text { Praderas de Posidonia (Posidonion } \\
\text { oceanicae) }\left({ }^{*}\right)\end{array}$ & $\begin{array}{l}5410 \text { Matorrales de tipo frigánico del } \\
\text { Mediterráneo occidental de cumbres } \\
\text { de acantilado (Astragalo-Plantaginetum } \\
\text { subulatae) }\end{array}$ \\
\hline 1130 Estuarios & $\begin{array}{l}5430 \text { Matorrales espinosos de tipo frigánico } \\
\text { endémicos del Euphorbio-Verbascion }\end{array}$ \\
\hline $\begin{array}{l}1140 \text { Llanos fangosos o arenosos que no } \\
\text { están cubiertos de agua cuando hay marea } \\
\text { baja }\end{array}$ & $\begin{array}{l}6110 \text { Prados calcáreos o basófilos de Alysso- } \\
\text { Sedion albi }\left(^{*}\right)\end{array}$ \\
\hline 1150 Lagunas costeras $(*)$ & $\begin{array}{l}6140 \text { Prados pirenaicos silíceos de Festuca } \\
\text { eskia }\end{array}$ \\
\hline 1160 Grandes calas y bahías poco profundas & $\begin{array}{l}6160 \text { Prados ibéricos silíceos de Festuca } \\
\text { indigesta }\end{array}$ \\
\hline 1170 Arrecifes & 6170 Prados alpinos y subalpinos calcáreos \\
\hline $\begin{array}{l}1180 \text { Estructuras submarinas causadas por } \\
\text { emisiones de gases }\end{array}$ & $\begin{array}{l}6210 \text { Prados secos seminaturales y facies de } \\
\text { matorral sobre sustratos calcáreos (Festuco- } \\
\text { Brometalia) (*parajes con importantes } \\
\text { orquídeas) }\end{array}$ \\
\hline $\begin{array}{l}1210 \text { Vegetación anual sobre desechos } \\
\text { marinos acumulados }\end{array}$ & $\begin{array}{l}6220 \text { Zonas subestépicas de gramíneas y } \\
\text { anuales de Thero-Brachypodietea }\left(^{*}\right)\end{array}$ \\
\hline $\begin{array}{l}1230 \text { Acantilados con vegetación de las } \\
\text { costas atlánticas y bálticas }\end{array}$ & $\begin{array}{l}6230 \text { Formaciones herbosas con Nardus, } \\
\text { con numerosas especies, sobre sustratos } \\
\text { silíceos de zonas montañosas (y de zonas } \\
\text { submontañosas de Europa continental) }\left(^{*}\right)\end{array}$ \\
\hline
\end{tabular}


TABLA 1 (cont.)

Tipos de Hábitats de Interés Comunitario presentes en España

\begin{tabular}{|c|c|}
\hline $\begin{array}{l}1240 \text { Acantilados con vegetación de las } \\
\text { costas mediterráneas con Limonium spp. } \\
\text { endémicos }\end{array}$ & 6310 Dehesas perennifolias de Quercus spp. \\
\hline $\begin{array}{l}1250 \text { Acantilados con vegetación endémica } \\
\text { de las costas macaronésicas }\end{array}$ & $\begin{array}{l}6410 \text { Prados con molinias sobre sustratos } \\
\text { calcáreos, turbosos o arcillo-limónicos } \\
\text { (Molinion caeruleae) }\end{array}$ \\
\hline $\begin{array}{l}1310 \text { Vegetación anual pionera con Salicornia } \\
\text { y otras especies de zonas fangosas o } \\
\text { arenosas }\end{array}$ & $\begin{array}{l}6420 \text { Prados húmedos mediterráneos de } \\
\text { hierbas altas del Molinion-Holoschoenion }\end{array}$ \\
\hline $\begin{array}{l}1320 \text { Pastizales de Spartina (Spartinion } \\
\text { maritimae) }\end{array}$ & $\begin{array}{l}6430 \text { Megaforbios eutrofos higrófilos de } \\
\text { las orlas de llanura y de los pisos montano } \\
\text { a alpino }\end{array}$ \\
\hline $\begin{array}{l}1330 \text { Pastizales salinos atlánticos (Glauco- } \\
\text { Puccinellietalia maritimae) }\end{array}$ & $\begin{array}{l}6510 \text { Prados pobres de siega de baja } \\
\text { altitud (Alopecurus pratensis, Sanguisorba } \\
\text { officinalis) }\end{array}$ \\
\hline $\begin{array}{l}1410 \text { Pastizales salinos mediterráneos } \\
\text { (Juncetalia maritimae) }\end{array}$ & 6520 Prados de siega de montaña \\
\hline $\begin{array}{l}1420 \text { Matorrales halófilos mediterráneos y } \\
\text { termoatlánticos (Sarcocornetea fruticosi) }\end{array}$ & 7110 Turberas altas activas $\left({ }^{*}\right)$ \\
\hline $\begin{array}{l}1430 \text { Matorrales halonitrófilos (Pegano- } \\
\text { Salsoletea) }\end{array}$ & $\begin{array}{l}7130 \text { Turberas de cobertura (* para las } \\
\text { turberas activas) }\end{array}$ \\
\hline $\begin{array}{l}1510 \text { Estepas salinas mediterráneas } \\
(\text { Limonietalia })(*)\end{array}$ & 7140 ‘Mires’ de transición \\
\hline $\begin{array}{l}1520 \text { Vegetación gipsícola ibérica } \\
\text { (Gypsophiletalia) }(*)\end{array}$ & $\begin{array}{l}7150 \text { Depresiones sobre sustratos turbosos } \\
\text { del Rhynchosporion }\end{array}$ \\
\hline 2110 Dunas móviles embrionarias & $\begin{array}{l}7210 \text { Turberas calcáreas de Cladium mariscus } \\
\text { y con especies del Caricion davallianae }(*)\end{array}$ \\
\hline $\begin{array}{l}2120 \text { Dunas móviles de litoral con Ammophila } \\
\text { arenaria (dunas blancas) }\end{array}$ & $\begin{array}{l}7220 \text { Manantiales petrificantes con } \\
\text { formación de tuf (Cratoneurion) }(*)\end{array}$ \\
\hline $\begin{array}{l}2130 \text { Dunas costeras fijas con vegetación } \\
\text { herbácea (dunas grises) }\left(^{*}\right)\end{array}$ & 7230 Turberas bajas alcalinas \\
\hline $\begin{array}{l}2150 \text { Dunas fijas descalcificadas atlánticas } \\
\text { (Calluno-Ulicetea) }\left(^{*}\right)\end{array}$ & $\begin{array}{l}7240 \text { Formaciones pioneras alpinas del } \\
\text { Caricion bicoloris-atrofuscae }(*)\end{array}$ \\
\hline 2190 Depresiones intradunales húmedas & $\begin{array}{l}8130 \text { Desprendimientos mediterráneos } \\
\text { occidentales y termófilos }\end{array}$ \\
\hline $\begin{array}{l}2210 \text { Dunas fijas de litoral del Crucianellion } \\
\text { maritimae }\end{array}$ & $\begin{array}{l}8210 \text { Pendientes rocosas calcícolas con } \\
\text { vegetación casmofítica }\end{array}$ \\
\hline 2230 Dunas con céspedes del Malcomietalia & $\begin{array}{l}8220 \text { Pendientes rocosas silíceas con } \\
\text { vegetación casmofítica }\end{array}$ \\
\hline
\end{tabular}


TABLA 1 (cont.)

Tipos de Hábitats de Interés Comunitario presentes en España

\begin{tabular}{|c|c|}
\hline $\begin{array}{l}2240 \text { Dunas con céspedes del } \\
\text { Brachypodietalia y de plantas anuales }\end{array}$ & $\begin{array}{l}8230 \text { Roquedos silíceos con vegetación } \\
\text { pionera del Sedo-Scleranthion o del Sedo } \\
\text { albi-Veronicion dillenii }\end{array}$ \\
\hline 2250 Dunas litorales con Juniperus spp. $\left(^{*}\right)$ & 8310 Cuevas no explotadas por el turismo \\
\hline $\begin{array}{l}2260 \text { Dunas con vegetación esclerófila de } \\
\text { Cisto-Lavanduletalia }\end{array}$ & $\begin{array}{l}8320 \text { Campos de lava y excavaciones } \\
\text { naturales }\end{array}$ \\
\hline $\begin{array}{l}2270 \text { Dunas con bosques Pinus pinea y/o } \\
\text { Pinus pinaster }\left({ }^{*}\right)\end{array}$ & $\begin{array}{l}8330 \text { Cuevas marinas sumergidas o } \\
\text { semisumergidas }\end{array}$ \\
\hline $\begin{array}{l}3110 \text { Aguas oligotróficas con un contenido } \\
\text { de minerales muy bajo de las llanuras } \\
\text { arenosas (Littorelletalia uniflorae) }\end{array}$ & 8340 Glaciares permanentes \\
\hline $\begin{array}{l}3140 \text { Aguas oligomesotróficas calcáreas con } \\
\text { vegetación béntica de Chara spp. }\end{array}$ & $\begin{array}{l}9120 \text { Hayedos acidófilos atlánticos con } \\
\text { sotobosque de llex y a veces de Taxus } \\
\text { (Quercion robori-petraeae o llici-Fagenion) }\end{array}$ \\
\hline $\begin{array}{l}3150 \text { Lagos eutróficos naturales } \\
\text { con vegetación Magnopotamion o } \\
\text { Hydrocharition }\end{array}$ & 9130 Hayedos del Asperulo-Fagetum \\
\hline 3160 Lagos y estanques distróficos naturales & $\begin{array}{l}9150 \text { Hayedos calcícolas medioeuropeos del } \\
\text { Cephalanthero-Fagion }\end{array}$ \\
\hline $\begin{array}{l}3170 \text { Estanques temporales mediterráneos } \\
(*)\end{array}$ & $\begin{array}{l}9160 \text { Robledales pedunculados o albares } \\
\text { subatlánticos y medioeuropeos del } \\
\text { Carpinion betuli }\end{array}$ \\
\hline 3190 Lagos sobre karst de yesos & $\begin{array}{l}9180 \text { Bosques de laderas, desprendimientos } \\
\text { o barrancos del Tilio-Acerion }\left({ }^{*}\right)\end{array}$ \\
\hline $\begin{array}{l}3220 \text { Ríos alpinos con vegetación herbácea } \\
\text { en sus orillas }\end{array}$ & $\begin{array}{l}\text { 91Bo Fresnedas termófilas de Fraxinus } \\
\text { angustifolia }\end{array}$ \\
\hline $\begin{array}{l}3230 \text { Ríos alpinos con vegetación leñosa en } \\
\text { sus orillas de Myricaria germanica }\end{array}$ & $\begin{array}{l}\text { 91Eo Bosques aluviales de Alnus glutinosa } \\
\text { y Fraxinus excelsior (Alno-Padion, Alnion } \\
\text { incanae, Salicion albae) }\left(^{*}\right)\end{array}$ \\
\hline $\begin{array}{l}3240 \text { Ríos alpinos con vegetación leñosa en } \\
\text { sus orillas de Salix elaeagnos }\end{array}$ & $\begin{array}{l}9230 \text { Robledales galaico-portugeses con } \\
\text { Quercus robur y Quercus pyrenaica }\end{array}$ \\
\hline $\begin{array}{l}3250 \text { Ríos mediterráneos de caudal } \\
\text { permanente con Glaucium flavum }\end{array}$ & $\begin{array}{l}9240 \text { Robledales ibéricos de Quercus faginea } \\
\text { y Quercus canariensis }\end{array}$ \\
\hline $\begin{array}{l}3260 \text { Ríos de pisos de planicie a montano } \\
\text { con vegetación de Ranunculion fluitantis y } \\
\text { de Callitricho-Batrachion }\end{array}$ & 9260 Bosques de Castanea sativa \\
\hline $\begin{array}{l}3270 \text { Rios de orillas fangosas con vegetación } \\
\text { de Chenopodion rubri p.p. y de Bidention } \\
\text { p.p. }\end{array}$ & $\begin{array}{l}\text { 92Ao Bosques galería de Salix alba y Populus } \\
\text { alba }\end{array}$ \\
\hline
\end{tabular}




\section{TABLA 1 (cont.)}

Tipos de Hábitats de Interés Comunitario presentes en España

\begin{tabular}{|c|c|}
\hline $\begin{array}{l}3280 \text { Ríos mediterráneos de caudal } \\
\text { permanente del Paspalo-Agrostidion con } \\
\text { cortinas vegetales ribereñas de Salix y } \\
\text { Populus alba }\end{array}$ & $\begin{array}{l}\text { 92Bo Bosques galería de ríos de caudal } \\
\text { intermitente mediterráneos con } \\
\text { Rhododendron ponticum, Salix y otras }\end{array}$ \\
\hline $\begin{array}{l}3290 \text { Ríos mediterráneos de caudal } \\
\text { intermitente del Paspalo-Agrostidion }\end{array}$ & $\begin{array}{l}\text { 92Do Galerías y matorrales ribereños } \\
\text { termomediterráneos (Nerio-Tamaricetea y } \\
\text { Securinegion tinctoriae) }\end{array}$ \\
\hline $\begin{array}{l}4020 \text { Brezales húmedos atlánticos de zonas } \\
\text { templadas de Erica ciliaris y Erica tetralix }\left(^{*}\right)\end{array}$ & 9320 Bosques de Olea y Ceratonia \\
\hline 4030 Brezales secos europeos & 9330 Alcornocales de Quercus suber \\
\hline $\begin{array}{l}4040 \text { Brezales secos atlánticos costeros de } \\
\text { Erica vagans }(*)\end{array}$ & $\begin{array}{l}9340 \text { Bosques de Quercus ilex y Quercus } \\
\text { rotundifolia }\end{array}$ \\
\hline 4050 Brezales macaronésicos endémicos $\left(^{*}\right)$ & $\begin{array}{l}9360 \text { Laurisilvas macaronésicas (Laurus, } \\
\text { Ocotea) }\left({ }^{*}\right)\end{array}$ \\
\hline 4060 Brezales alpinos y boreales & 9370 Palmerales de Phoenix $\left(^{*}\right)$ \\
\hline $\begin{array}{l}4090 \text { Brezales oromediterráneos endémicos } \\
\text { con aliaga }\end{array}$ & 9380 Bosques de Ilex aquifolium \\
\hline $\begin{array}{l}5110 \text { Formaciones estables xerotermófilas } \\
\text { de Buxus sempervirens en pendientes } \\
\text { rocosas (Berberidion p.p.) }\end{array}$ & $\begin{array}{l}9430 \text { Bosques montanos y subalpinos de } \\
\text { Pinus uncinata (* en sustratos yesosos o } \\
\text { calcáreos) }\end{array}$ \\
\hline $\begin{array}{l}5120 \text { Formaciones montanas de Cytisus } \\
\text { purgans }\end{array}$ & 9520 Abetales de Abies pinsapo \\
\hline $\begin{array}{l}5130 \text { Formaciones de Juniperus communis en } \\
\text { brezales o pastizales calcáreos }\end{array}$ & $\begin{array}{l}9530 \text { Pinares (sud-)mediterráneos de pinos } \\
\text { negros endémicos }(*)\end{array}$ \\
\hline $\begin{array}{l}5210 \text { Matorral arborescente con Juniperus } \\
\text { spp. }\end{array}$ & $\begin{array}{l}9540 \text { Pinares mediterráneos de pinos } \\
\text { mesogeanos endémicos }\end{array}$ \\
\hline $\begin{array}{l}5220 \text { Matorrales arborescentes con Ziziphus } \\
(*)\end{array}$ & 9550 Pinares endémicos canarios \\
\hline $\begin{array}{l}5230 \text { Matorrales arborescentes con Laurus } \\
\text { nobilis }(*)\end{array}$ & $\begin{array}{l}9560 \text { Bosques endémicos de Juniperus spp. } \\
(*)\end{array}$ \\
\hline \multirow{2}{*}{$\begin{array}{l}5320 \text { Formaciones bajas de euphorbia } \\
\text { próximas a acantilados }\end{array}$} & 9570 Bosques de Tetraclinis articulata (*) \\
\hline & $\begin{array}{l}9580 \text { Bosques mediterráneos de Taxus } \\
\operatorname{baccata}(*)\end{array}$ \\
\hline
\end{tabular}

Las necesidades de conocimiento de los tipos de HIC se han incrementado con el paso de los años, especialmente por las obligaciones que emanan de la Directiva 150 92/43/CEE en lo que se refiere a la evaluación y al seguimiento del estado de conser- 
vación de los tipos de hábitats y de las especies de interés comunitario. En este contexto, el Ministerio de Medio Ambiente y Medio Rural y Marino acaba de publicar en formato digital las "Bases ecológicas preliminares para la conservación de los tipos de hábitat de interés comunitario en España" (MARM, 2009). El resultado de este trabajo ha sido la redacción de una ficha general o documento científico para cada uno de los 117 tipos de HIC presentes en España, además de un documento global para algunos grupos o subgrupos de tipos de hábitats como son las dunas, los ecosistemas lénticos (aguas retenidas), los ecosistemas lóticos (ríos) o las turberas. Cada ficha se estructura en siete capítulos entre los que cabe destacar el de caracterización ecológica y el de evaluación del estado de conservación. Para cada tipo de HIC se establecen subtipos o grupos funcionales, se comentan los factores biofísicos que permiten entender los elementos estructurales y de función, se establecen sus exigencias o requerimientos ecológicos y se proponen procedimientos estandarizados para evaluar el estado de conservación a escala local. Esta obra debe considerarse un punto de referencia fundamental para sistematizar el conocimiento sobre los atributos de composición, estructura y función que caracterizan a los tipos de HIC, e incluso como base para la caracterización de otros ecosistemas españoles no catalogados como HIC. Mas adelante se recoge algunos extractos de este trabajo al analizar ciertos aspectos de algunos sistemas naturales.

La situación latitudinal del territorio español en la zona templada del globo (entre los paralelos $35 .^{\circ}$ y $45 .^{\circ}$ Norte) define primordialmente el factor climático de España. Este hecho, unido a las especiales características orográficas (relieve y altitud), edáficas, litológicas e hidrográficas conforman un complejo mosaico ambiental en el que conviven varias decenas de miles de especies ${ }^{8}$. Aunque el territorio español no puede considerarse un país megadiverso en el ámbito mundial, atesora sistemas ecológicos francamente originales como son los ambientes mediterráneos, caracterizados por la confluencia en el verano de altas temperaturas (máxima evapotranspiración) y mínimas o nulas precipitaciones, lo que provoca unos condicionantes ambientales muy severos para el desarrollo de plantas y animales. La región semiárida murciano-almeriense o los paisajes esteparios, con su singularidad florística y faunística, constituyen paisajes únicos en el seno de la Unión Europea (Suarez et al, 1991). El Archipiélago Canario, con su conjunto de islas oceánicas de origen volcánico, está situado entre los 27 y $30 .^{\circ}$ de latitud norte e influenciado notablemente por el régimen de los vientos alisios. Las islas constituyen territorios claramente delimitados en los que se producen procesos ecológicos y evolutivos muy interesantes cuyo estudio ha servido para el avance de disciplinas como la biogeografía, la evolución o la ecología. Las islas Canarias atesoran también sistemas naturales muy originales como la laurisilva canaria, un bosque subtropical perennifolio que representa una reliquia de la era terciaria.

$8 \quad$ No es posible dar un número más o menos aproximado del total de especies existentes si consideramos absolutamente todos los tipos de organismos vivos, desde los vertebrados más conspicuos hasta los organismos unicelulares. El conocimiento es incompleto o muy incompleto para grupos como los invertebrados. 


\section{RIQUEZA FLORÍSTICA}

En términos de riqueza, es decir, número de especies, la flora vascular española (helechos y plantas con flores) contiene el mayor número en el contexto europeo a excepción de Turquía. En la tabla 2 se incluyen datos de diversidad (número de especies/log de la superficie territorial) para 12 países europeos. Aunque es difícil dar una cifra precisa podemos considerar que hay entre 8.000 y 9.000 taxones: 7.000 en el territorio peninsular, 1.700 en las Baleares y 1.900 en Canarias. Los patrones de riqueza florística están relacionados con la heterogeneidad ambiental (relieve, sustratos o clima). Las montañas ibéricas son las zonas donde encontramos mayor diversidad, no sólo por la variedad de hábitats que existen sino también por el menor grado de alteración antrópica. Por el contrario, las mesetas y las grandes cuencas endorreicas y fluviales interiores, mucho más transformadas y con menor variedad de hábitat, atesoran menor diversidad (VVAA, 2005). Además, el número de especies endémicas, es decir, exclusivas de nuestro país, es también muy alto y se encuentra alrededor de 1.550 especies y subespecies. En las Islas Canarias encontramos que el porcentaje de endemicidad (número de especies endémicas con respecto al total de la flora) se encuentra alrededor del 30\% (unos 560 taxones). Zonas con altas tasas de endemicidad son además las montañas Béticas, Baleares, los Pirineos, la Cordillera Cantábrica y el sureste-ibérico. Sierra Nevada, con 66 endemismos representa el territorio europeo con mayor número de plantas endémicas por unidad de superficie.

TABLA 2

Diversidad de la flora vascular española*

\begin{tabular}{|c|c|}
\hline País & $\begin{array}{c}\text { Diversidad de Plantas Vasculares (= número } \\
\text { de especies / logaritmo de la superficie territorial) }\end{array}$ \\
\hline Alemania & 483 \\
\hline Bélgica & 324 \\
\hline Dinamarca & 270 \\
\hline España & 1401 \\
\hline Francia & 805 \\
\hline Grecia & 969 \\
\hline Holanda & 264 \\
\hline Irlanda & 195 \\
\hline Italia & 1021 \\
\hline Luxemburgo & 365 \\
\hline Portugal & 518 \\
\hline Reino Unido & 301 \\
\hline
\end{tabular}

Documentación Administrativa 
En lo que a géneros se refiere, en la Península y Baleares hay aproximadamente 1.200 y en Canarias 680 (Simón, 1994). De ellos, 23 son endémicos del territorio ibérico-balear (Blanco y Simón, 1994) y 19 endémicos de Canarias (Arco Aguilar, 1989). De las 350 familias de plantas vasculares existentes en el mundo, 175 (sin contar helechos) se encuentran representadas en España aunque sólo cinco tiene gran relevancia: compuestas, gramíneas, leguminosas, crucíferas y cariofiláceas (Blanco, 2002).

Desde un punto de vista biogeográfico, aproximadamente la mitad de las especies que componen nuestra flora son de distribución mediterránea, un 15\% son euroasiáticas, otro $15 \%$ son endemismos de nuestro país y un $10 \%$ son especies cosmopolitas (de amplia distribución). Otros elementos florísticos representados en menor medida son el macaronésico (Islas Canarias) y el norteafricano.

La región bioclimática mediterránea es uno de los 34 hotspots (puntos calientes) de biodiversidad identificados en todo el mundo puesto que atesora entre 25.00030.000 especies y subespecies, es decir, un 10\% de la plantas superiores del globo en apenas el $1.6 \%$ de la superficie terrestre (Médail, 2009). Dentro de los hotspots de diversidad vegetal en dicha región se encuentran el complejo Bético-Rifeño y las islas occidentales mediterráneas (Baleares, Córcega, Cerdeña y Sicilia).

Las listas o libro rojos de especies amenazas son el procedimiento más extendido para evaluar el estado en el que se encuentra la biota de un territorio. Los taxones estudiados se catalogan en una de las 10 categorías definidas por la UICN en función de una serie de criterios como son, entre otros, la reducción del contingente total de individuos maduros o la distribución geográfica reducida. Las categorías que implican amenaza son Extinto, En Peligro Crítico, En Peligro y Vulnerable. En España hay que destacar la Lista Roja de la Flora Vascular del año 2000, el Atlas y Libro Rojo (Moreno et al, 2003) y la reciente Lista Roja del 2008 (Moreno, 2009). Es complejo contestar a la pregunta de si está aumentando el número de especies amenazadas, ya que se afinan los procedimientos de evaluación con el paso del tiempo y hay cambios en la taxonomía de los taxones. No obstante, los datos sugieren que sí se está produciendo un incremento: en 1984 se contaron 1.095 taxones extintos o amenazados, en la Lista Roja de 2000 hubo 1.149 y en la lista de 2008 suman 1.221 (tabla 3). Los territorios con mayor número de taxones amenazados coinciden en general con los que contienen mayor número de endemismos. No es de extrañar, entonces, que las Islas Canarias, Andalucía (Sierras Béticas), los Pirineos o la Cordillera Cantábrica alberguen muchas especies amenazadas.

El Atlas y Libro Rojo de 2003 permitió un estudio cuantitativo de las amenazas a las que están sometidas las poblaciones de los taxones estudiados. De este análisis se deriva que los principales problemas de conservación para el conjunto de la flora se deben a la destrucción, degradación y fragmentación de los hábitats naturales, así como a los cambios en el uso del suelo. El sobrepastoreo, el pisoteo y la artificialización de los terrenos son las amenazas debidas a acciones humanas que afectan a mayor número de poblaciones estudiadas. 


\section{TABLA 3}

Número de taxones de la Lista Roja de 2000 y de la Lista Roja 2008 según sus categorías UICN de amenaza (1994 y 2001 respectivamente)

\begin{tabular}{|l|c|c|}
\hline \multicolumn{1}{|c|}{ Categoría de amenaza } & LR 2000 & LR 2009 \\
\hline EX, EW o RE (extinto) & 21 & 25 \\
\hline CR (En peligro crítico) & 164 & 308 \\
\hline EN (En peligro) & 244 & 278 \\
\hline VU (Vulnerable) & 720 & 610 \\
\hline NT (Casi amenazado) & - & 172 \\
\hline DD (Datos insufiicentes) & 265 & 133 \\
\hline LC (Preocupación menor) & - & 45 \\
\hline
\end{tabular}

Fuente: Moreno, 2009.

Las proyecciones de cambio climático para finales del siglo en el suroeste de Europa apuntan a un ascenso general de las temperaturas, una reducción de las disponibilidades hídricas y un aumento de la variabilidad climática. Entre las consecuencias directas de estos impactos cabe destacar la ampliación del período de actividad vegetativa, disminuciones de la productividad potencial o desplazamientos altitudinales y latitudinales (VVAA, 2009).

\section{LOS SISTEMAS NATURALES ESPAÑOLES}

Para abordar una descripción en términos generales de los sistemas naturales consideramos conveniente hacer una distinción en tres grandes medios: el medio terrestre, el medio acuático continental y el medio costero y marino. A grandes rasgos son especialmente diferentes las características ecológicas del medio marino frente al terrestre ya que en el primero hay mayor conectividad (menos fronteras) y menor variación estacional por la inercia térmica del agua, además de una marcada tridimensionalidad y diferentes factores reguladores de la producción biológica.

\section{El medio terrestre}

En la Península Ibérica pueden sintetizarse dos zonas climáticas básicas: la mediterránea (que ocupa la mayor parte del territorio e incluye a las Islas Baleares) y la similar a la atlántico-centroeuropea. Esta última ocupa la franja norte que se corresponde básicamente con gran parte de Galicia, Asturias, Cantabria, País Vasco y los Pirineos. La sequía estival del mediterráneo, el efecto atemperador de las temperaturas que producen las grandes masas de agua que rodean la península y la continenta-

154 lidad (mayores oscilaciones de temperatura y precipitaciones) de las zonas interiores 
son rasgos básicos de nuestra climatología. Sin embargo, una elevada altitud media (casi el 60\% de la superficie por encima de los $600 \mathrm{~m}$ ), la disposición periférica de las principales cordilleras y una serie de sistemas montañosos interiores como el Sistema Central o el Sistema Ibérico, generan unos condicionantes ambientales que permiten distinguir subzonas o sectores climáticos con diferentes características (diferencias topoclimáticas). En cuanto a la litología, el factor diferenciador más relevante se refiere a la presencia de suelos silíceos (ácidos) o calizos (básicos). El territorio silíceo se centra básicamente en la parte occidental y el calizo en la oriental. No obstante, los ambientes mediterráneos se encuentran entre los más diversos del mundo y la diversidad de edafotaxa (tipos de suelo) por unidad de área, bajo clima mediterráneo, es la mayor del globo, siendo la Península la más edafodiversa de la vertiente norte de la Cuenca Mediterránea (Ibáñez y García, 2002). Los ambientes mediterráneos presentan una distribución discontinua en la Tierra que no sólo se restringe a las áreas que circundan este mar por Europa, Norte de África y Oriente próximo. Las zonas de clima mediterráneo se localizan también al oeste de Estados Unidos (principalmente California) y en el hemisferio sur (entre los 30 y $400^{\circ}$ de latitud): concretamente en Chile, en la Región Capense (Sudáfrica) y en el suroeste de Australia. En cuanto a la Península Ibérica, las mayores diferencias entre los subtipos mediterráneos se deben a la precipitación media anual y a la duración del período con probabilidad de heladas: los subtipos continentales (invierno largo y con frecuencia poco lluvioso) apenas se encuentran en la periferia del Mar Mediterráneo (Gómez Sal, 2007).

El concepto de ecosistema o de comunidad no deja de ser algo etéreo y, por consiguiente, difícil de precisar, sobre todo si tenemos en cuenta todos los organismos que podemos encontrar en un territorio dado. Para simplificar el análisis de la complejidad del mundo real en el medio terrestre (no en el oceánico) se suele utilizar a la vegetación (sobre todo a las plantas vasculares) como descriptor de los ecosistemas-comunidades. Sin embargo, el estudio de la comunidad vegetal (un ejemplo de taxocenosis) no está exento de limitaciones importantes tal como señala Terradas (2001 al decir que en la comunidad vegetal se incluyen generalmente organismos emparentados taxonómicamente, muy distintos en tamaño y función, cuyas relaciones son enormemente asimétricas, y se suele excluir, en cambio, a organismos decisivos par la vida de las plantas, como fitófagos, detritívoros, descomponedores, polinizadores, diseminadores, etc. Si ello es así, la comunidad vegetal es, sin duda, un ente artificioso, producto de nuestra limitación para observar un sistema más complejo. La comunidad es un ente en el que agrupamos organismos no tanto por sus reales conexiones funcionales como por su pertenencia a un grupo taxonómico particular y sus similar localización espacial.

Dado que no hay una clasificación ecosistémica del territorio español, la vegetación (fitocenosis) puede ser un atributo importante del medio terrestre que sirva para su caracterización, aunque no hay que olvidar, además de las limitación expuestas anteriormente, que en determinados sistemas ecológicos, los procesos abióticos son muy importantes para explicar los factores de estructura y función. No obstante, el avance de las técnicas de teledetección está permitiendo una caracterización fun- 
cional importante de los ecosistemas. En este sentido, por ejemplo, puede mencionarse la clasificación de Tipos Funcionales de Ecosistemas de la Península Ibérica, a partir de imágenes NOAA, basada en tres atributos de las curvas estacionales del Índice Verde Normalizado (NDVI): la integral anual (NDVI-I), el rango relativo (RREL) y la época en que se alcanza el máximo (MMAX) (Alcaraz-Segura et al., 2004). En este trabajo se han definido 53 tipos de ecosistemas funcionales y se han identificado dos grandes zonas: una con máximos de verano, baja estacionalidad y alta productividad correspondiente a la Región Eurosiberiana y las principales cadenas montañosas mediterráneas; y otra con mayor estacionalidad y productividad y máximos en las otras estaciones del año, para el resto del territorio.

Si bien puede decirse que la mayor parte del territorio español terrestre tiene una clara vocación forestal, no está tan claro qué tipo de masas forestales (en composición y estructura) tuvieron mayor o menor importancia fisonómica, sobre todo en biotopos con condicionantes no macroclimáticos. El relieve, la litofacies y la acción humana son causas primarias que explican la actual estructura espacial del paisaje en forma de mosaicos.

Desde un punto de vista estructural predominan las dehesas, los montes huecos, matorrales, pastizales leñosos, pastizales xerófitos, pinares naturales y artificiales, montes de matas de frondosas y bosques mixtos de frondosas y coníferas. Las comunidades zonales (dependientes del clima) pueden describirse atendiendo a su distribución altitudinal en tres tipos: tipos suprasílvicos (por encima del límite altitudinal superior del bosque), sílvicos (pisos altitudinales y climáticos compatibles con el desarrollo de masas arboladas) e infrasílvicos (por debajo del límite de disponibilidad de agua para desarrollar bosques). Las estructuras zonales en Canarias comprenden formaciones de alta montaña, vegetación sílvica caracterizada por los pinares de pino canario, la laurisilva y el fayal-brezal y tipos infrasílvicos como los sabinares, los cardonales y los tabaibales (Ruiz de la Torre, 1990, 2002). Muchas de estas formaciones vegetales son identificables como tipos de HIC e incluidas en los grupos cuatro (brezales), cinco (matorrales esclerófilos), seis (prados y pastizales) y nueve (bosques). Las dehesas constituidas por especies del género Quercus se corresponden, por ejemplo, con el tipo de HIC 6310.

Los tipos estructurales azonales están condicionados por la naturaleza o cualidades del sustrato. De esta forma es posible encontrar comunidades vegetales dulceacuícolas, halohidrófilas (agua salada, salina o salobre), haloxerófilas (sal y sequía), gipsófilas (yeso), arenícolas (dunas y arenales móviles litorales y continentales) o rupícolas.

En lo que concierne a las masas arboladas, podemos considerar cinco grandes grupos de estructuras (Costa, Morla y Sainz, 1997):

- Bosques planocaducifolios de carácter atlántico, ya sean monoespecíficos (dominados por una sola especie) o integrados por muy diversas especies. Se 
incluyen aquí hayedos, robledales, alisedas, fresnedas, choperas, olmedas, abedulares y bosques mixtos de frondosas atlánticas).

- Formaciones aciculifolias montanas y subalpinas. Son los pinares de pino albar y pino negro y los abetales.

- Bosques caducifolios o semicaducifolios (marcescentes) de carácter sudatlántico o submediterráneo. Incluye los melojares y los quejigares.

- Bosques esclerófilos mediterráneos, monoespecíficos o mixtos, frecuentemente acompañados por coníferas xerófilas. Se incluyen aquí los encinares, los alcornocales y los acebuchales.

- Bosques mediterráneos de coníferas, tanto basales como mediterráneo-montanos, monoespecíficos o mixtos entre sí y con frondosas. Son los pinares de pino negral, pino resinero, pino piñonero y pino carrasco, así como los sabinares albares.

La gran mayoría de estas formaciones arboladas o boscosas (tabla 4) se encuentran perfectamente representadas en el Anexo I de la Directiva 92/43/CEE, es decir, son claramente tipos de HIC. Sólo algunas formaciones como los robledales atlánticos, los abedulares, los abetales de abeto blanco o los pinares de pino albar se encuentran excluidos. Además de bosques de extensión más o menos amplia, la Directiva 92/43/CEE incluye también como tipos de HIC a formaciones de distribución muy restringida como son los bosques mixtos caducifolios situados en barrancos y pies de cantiles (9180), los abetales de Abies pinsapo (pinsapares) (9520), las formaciones de araar o sabina mora (Tetraclinis articulata) (9570) o los menguados palmerales canarios de Phoenix canariensis (9370).

TABLA 4

Tipología de bosques ibéricos y de Canarias (Costa, Morla, Sainz, 1997)

\begin{tabular}{|l|l|}
\hline Abetales (Abies alba) & $\begin{array}{l}\text { Encinares-carrascales interiores } \\
\text { continentales }\end{array}$ \\
\hline Hayedos (Fagus sylvatica) & Alcornocales \\
\hline Bosques mixtos atlánticos & Sabinares albares (Juniperus thurifera) \\
\hline Robledales o carballeidas (Quercus robur) & Sabinares negrales (Juniperus phoenicea) \\
\hline Robledales albares (Quercus petraea) & Enebrales (Juniperus oxycedrus) \\
\hline Pinares de Pino negro (Pinus uncinata) & Pinsapares (Abies pinsapo) \\
\hline Pinares de pino albar (Pinus sylvestris) & Pinares de pino carrasco (Pinus halepensis) \\
\hline Abedulares (Betula alba/pendula) & Pinares de pino piñonero (Pinus pinea) \\
\hline Acebedas (Ilex aquifolium) & Pinares de pino negral (Pinus pinaster) \\
\hline
\end{tabular}


TABLA 4 (cont.)

Tipología de bosques ibéricos y de Canarias (Costa, Morla, Sainz, 1997)

\begin{tabular}{|l|l|}
\hline Lauredales (Laurus nobilis) & $\begin{array}{l}\text { Pinares de pino salgareño (Pinus nigra subsp. } \\
\text { salzmanii) }\end{array}$ \\
\hline Tejedas (Taxus baccata) & Pinares de pino albar (Pinus sylvestris) \\
\hline Tilares (Tilia cordata/platyphyllos) & Bosques mixtos submediterráneos \\
\hline Temblares (Populus tremula) & Madroñales (Arbutus unedo) \\
\hline Avellanedas (Corylus avellana) & Loreras (Prunus lusitanica) \\
\hline $\begin{array}{l}\text { Quejigares de roble pubescente (Quercus } \\
\text { humilis) }\end{array}$ & Formaciones de araar (Tetraclinis articulata) \\
\hline Melojares (Quercus pyrenaica) & Bosque termófilo seco (Canarias) \\
\hline Quejigares(Quercus faginea) & Laurisilva (Canarias) \\
\hline Alsinares (Quercus ilex subsp. Ilex) & Fayal-brezal (Canarias) \\
\hline Encinares cantábricos & Pinares de pino canario (Pinus canariensis) \\
\hline
\end{tabular}

Un tercio de la superficie de España puede estar ocupado por matorrales y arbustedos (dominados por arbustos), con un significado ecológico diferencial según se consideren etapas seriales de la sucesión (con alto o con bajo valor evolutivo) o comunidades permanentes (particulares condiciones del suelo). Entre los matorrales y arbustedos permanentes podemos diferenciar los que se deben al frío, a la sequía o al suelo (tabla 5). Prácticamente todos estos matorrales permanentes y otros seriales de alto valor evolutivo, como los bosquetes frutescentes, los coscojares u otros arbustedos mediterráneos, son tipos de HIC.

\section{TABLA 5}

Tipos principales de matorrales y arbustedos permanentes (San Miguel et al., 2004)

Comunidades de enebros (Juniperus communis subsp. nana y J. c. subsp. hemisphaerica) y sabinas rastreras (J. sabina)

Piornales de Cytisus oromediterraneus

Comunidades de ericáceas de alta montaña y de sauces enanos

Erizonales

Comunidades de rosáceas espinosas de alta montaña

Coscojares de Quercus coccifera

Arteales de Ziziphus lotus

Palmitares de Chamaerops humilis

Cornicales (Periploca angustifolia, Withania frutescens y Maytenus senegalensis)

Matorrales retamoides semiáridos béticos y murciano-almerienses

Enebrales y sabinares costeros y los matorrales de dunas fijadas

Matorrales y arbustedos de espolones, roquedos y crestas

Comunidades salinas dominadas por quenopodiáceas suculentas

158 Matorrales gipsófilos, dolomitícolas, serpentinícolas 
Las comunidades herbáceas naturales y seminaturales pueden cubrir también un tercio del territorio nacional, siendo la mayoría etapas seriales que proceden de la alteración antrópica; sólo las comunidades de alta montaña podrían considerarse de carácter permanente, aunque han sido tradicionalmente modificadas para dar alimento al ganado. Como pastos son muy importantes para la ganadería y los herbívoros silvestres, pudiendo contener altos valores de diversidad biológica. Su gestión activa es fundamental para que puedan seguir manteniéndose en un estado de conservación favorable. En general están bien representadas en la tipología de tipos de HIC.

En cuanto a los factores biofísicos y antrópicos que regulan los atributos de composición, estructura y función, es todavía mucho lo que queda por estudiar para establecer modelos relativamente aceptables que identifiquen aquellos factores clave que controlan los procesos de organización de las comunidades. Esto puede ser especialmente complicado en las comunidades herbáceas, que pueden tener una extensión reducida, configurar complicados mosaicos, ser muy dinámicas y depender del ganado o de los herbívoros silvestres. En lo que respecta al atributo composicional, falta una inventariación razonablemente completa de muchas zonas del territorio en diferentes grupos biológicos. Además de los factores ambientales determinantes según los casos, como pueden ser el suelo, el relieve o los regímenes de precipitación y temperatura, hay que abordar los procesos que regulan el funcionamiento sistémico del medio, por ejemplo la función de la diversidad biológica en la estabilidad de los ecosistemas, considerando no sólo la riqueza y abundancia de especies sino la intensidad y complejidad de las relaciones interespecíficas (relaciones tróficas, mutualistas, etc.). Es importante también considerar otros factores como son la regeneración por mecanismos de facilitación, la colonización-recolonización a partir de la capacidad dispersiva de las especies, los patrones de heterogeneidad espacial o las respuestas diferenciales al estrés hídrico en la región mediterránea (ver por ejemplo Valladares, 2004).

Otros tipos de sistemas naturales en el medio terrestre son aquellos en los que la vegetación es un atributo poco relevante. Nos referimos a los sistemas rocosos reconocidos como tipos de HIC (grupo ocho): laderas y desprendimientos, cuevas, campos de lava y glaciares permanentes. Son todos ellos sistemas dependientes en términos generales de la diversidad litológica, de la estructura (características mineralógicas del sustrato y configuración tectónica), de la dinámica de ladera o del clima (caso de los glaciares sobre todo). En la tabla 6 se recogen, por ejemplo, los procesos y formas de modelado del tipo de HIC 8320 (campos de lava y excavaciones naturales).

Entre los problemas de conservación que afectan a los ecosistemas del medio terrestre cabe destacar la amenaza del cambio climático y otras presiones generales como son, para los bosques, la pérdida y fragmentación de la superficie forestal, la corta de árboles antes de alcanzar la madurez fisiológica (disminución de madera muerta y especies asociadas), la modificación de las masas por silvicultura y el establecimiento de estructuras forestales no naturales así como la realización de plantaciones forestales (especies nativas o autóctonas) (AEMA, 2008). A estas presiones hay que añadir la destrucción directa por artificialización del territorio (tejido urbano, infraestructuras), los incendios forestales o la presión del ganado. 
TABLA 6

Procesos y formas de modelado del hábitat 8320. Campos de lava y excavaciones naturales

\begin{tabular}{|c|c|c|}
\hline \multirow[b]{2}{*}{ Subtipos } & \multicolumn{2}{|c|}{ Morfoestructuras } \\
\hline & $\begin{array}{l}\text { Edificios volcácnicos } \\
\text { y campos de } \\
\text { piroclastos }\end{array}$ & Superficies lávicas \\
\hline $\begin{array}{l}\text { Territorios volcánicos recientes en ambiente } \\
\text { climático cálido con lluvias inferiores a } \\
350 \mathrm{~L} / \mathrm{m}^{2}\end{array}$ & $\begin{array}{l}\text { - Torrenciales (3) } \\
\text { - Gravedad (2) } \\
\text { - Marinos (4) } \\
\text { - Eólicos (3) } \\
*\end{array}$ & $\begin{array}{l}\text { - Torrenciales (1) } \\
\text { - Gravedad (1) } \\
\text { - Marinos (3) } \\
\text { - Eólicos (1) } \\
*\end{array}$ \\
\hline $\begin{array}{l}\text { Territorios volcánicos recientes en ambiente } \\
\text { climático templado-cálido con lluvias entre } \\
\left.200-600 \mathrm{~L} / \mathrm{m}^{2}\right)\end{array}$ & $\begin{array}{l}\text { - Torrenciales (3) } \\
\text { - Gravedad (2) } \\
\text { - Eólicos (3) } \\
*\end{array}$ & $\begin{array}{l}\text { - Torrenciales (3) } \\
\text { - Gravedad (2) } \\
\text { - Eólicos (3) } \\
*\end{array}$ \\
\hline $\begin{array}{l}\text { Territorios volcánicos recientes en ambiente } \\
\text { templado con lluvias entre } 300-1100 \mathrm{~L} / \mathrm{m}^{2}\end{array}$ & $\begin{array}{l}\text { - Torrenciales (2) } \\
\text { - Gravedad (2) } \\
\text { - Eólicos (1) }\end{array}$ & $\begin{array}{l}\text { - Torrenciales (2) } \\
\text { - Gravedad (1) } \\
\text { - Eólicos (1) }\end{array}$ \\
\hline $\begin{array}{l}\text { Territorios volcánicos recientes en ambiente } \\
\text { climático fresco con lluvias superiores a } \\
700 \mathrm{~L} / \mathrm{m}^{2}\end{array}$ & $\begin{array}{l}\text { - Torrenciales (3) } \\
\text { - Gravedad (2) } \\
\text { - Eólicos (3) }\end{array}$ & $\begin{array}{l}\text { - Torrenciales (3) } \\
\text { - Gravedad (1) } \\
\text { - Eólicos (1) }\end{array}$ \\
\hline $\begin{array}{l}\text { Territorios volcánicos recientes en ambiente } \\
\text { climático frío con precipitaciones entre } 400 \text { - } \\
800 \mathrm{~L} / \mathrm{m}^{2}\end{array}$ & $\begin{array}{l}\text { - Torrenciales (3) } \\
\text { - Gravedad (4) } \\
\text { - Eólicos (3) } \\
\text { - Hielo (4) }\end{array}$ & $\begin{array}{l}\text { - Torrenciales (2) } \\
\text { - Gravedad (2) } \\
\text { - Eólicos (2) } \\
\text { - Hielo (4) }\end{array}$ \\
\hline
\end{tabular}

Intensidad de cada uno de los procesos: 1 = incipiente, 2 = débil, 3 = moderada y 4 = intensa.

* Intervención antropica (excavaciones, extracciones, edificaciones, etc.).

Fuente: Bertrán y Dóniz, 2009.

Entre los posibles efectos del cambio climático cabe mencionar el aumento de la productividad en la Región Atlántica y su disminución en la Mediterránea, alteración de la fenología y de las interacciones entre especies, cambios edáficos o cambios en el régimen de incendios, simplificación estructural y extinciones locales. La vegetación de alta montaña, los bosques y arbustedas caducifolios sensibles a la sequía estival, los bosques esclerófilos y lauroides del sur y suroeste peninsular y la vegetación litoral se cuentan entre los tipos más vulnerables (VVAA, 2005).

Desde un punto de vista estratégico, la diversa normativa comunitaria en materia forestal (varias comunicaciones y Estrategia forestal de 1998) así como la Ley de Montes (Ley 42/2003 y Ley 10/2006), La Estrategia Forestal Española (1999) y el Plan Forestal Español (2002), recogen perfectamente las necesidades de coordinación e 160 integración del sector forestal con el de la ordenación de los recursos naturales, fun- 
damentalmente a través del concepto de desarrollo sostenible. Es importante mencionar que los Planes de Ordenación de los Recursos Forestales (PORF) deben considerar la necesaria regulación de los aprovechamientos forestales con el mantenimiento de un estado de conservación favorable en el caso de los tipos de HIC, así como una armonización con las estrategias y planes de conservación y restauración de los hábitats en peligro de desaparición (Ley 42/2007). En cualquier caso, queda pendiente llevar a cabo un proyecto técnico-científico de ámbito estatal que aborde de forma sistemática la problemática y la evaluación del estado de conservación de nuestros ecosistemas terrestres.

\section{El medio acuático continental}

En este epígrafe incluimos los ecosistemas lénticos (aguas retenidas) y los ecosistemas lóticos (aguas corrientes), incluidos básicamente en el grupo 3 de los tipos de HIC. Si bien la Directiva 92/43/CEE ha supuesto un hito importante en el impulso de trabajos de inventariación y caracterización de ecosistemas, la Directiva 2000/60/CE Directiva marco del agua (DMA) representa sin lugar a dudas un hito fundamental en el estudio, análisis y planificación de los recursos hídricos.

El núcleo central de la DMA se basa en mantener el buen estado ecológico de las aguas superficiales y el buen estado de las aguas subterráneas. Y el estado ecológico se define como una expresión de la calidad de la estructura y el funcionamiento de los ecosistemas acuáticos asociados a las aguas superficiales. Existe por tanto una marcada analogía entre el estado ecológico de la DMA y el estado de conservación de los hábitats y de las especies de la Directiva 92/43/CEE. Sin embargo, la DMA presenta un mayor desarrollo al establecer un proceso metodológico de aplicación más completo y preciso, en el que se incluye una tipología de los distintos tipos de aguas, una clasificación de estados ecológicos, unos indicadores de calidad (biológicos, hidromorfológicos y químicos-fisicoquímicos) y un sistema de seguimiento.

Las aguas superficiales, según la DMA, comprenden las aguas continentales (excepto las subterráneas), las aguas de transición (masas próximas a la desembocadura de los ríos) y las aguas costeras. Las aguas superficiales continentales se subdividen en ríos, lagos y masas de agua superficiales artificiales y muy modificadas. España contribuye con un total de 4.630 masas de agua superficiales, de las que 3.792 son ríos y 319 son lagos (168 son aguas de transición y 351 son aguas costeras).

Tal como se observa en la tabla 7, los factores biofísicos que permiten entender el funcionamiento de los ecosistemas lénticos son numerosos y responden tanto a factores físicos como físico-químicos y biológicos. Aunque hay diferentes tipologías de estos ecosistemas, es necesario actualizar el inventario español de zonas húmedas para abordar con rigor una clasificación lo más consensuada posible que permita identificar la ecodiversidad de estos sistemas ecológicos. En este sentido, hay que tener en cuenta que España incluye la mayor diversidad de tipos de zonas húmedas 
de Europa, destacando la originalidad de los lagos kársticos sobre yesos y especialmente la de nuestras lagunas salinas. Una clasificación simplificada atendiendo a grupos funcionales podría contener los siguientes ocho tipos: lagunas y humedales fluviales, sistemas de alta montaña, lagos y lagunas profundos kársticos calcáreos y sobre yesos, lagunas someras salinas, lagunas y humedales someros no salinos de aguas alcalinas y de aguas ácidas y lagunas volcánicas (Camacho et al., 2009).

TABLA 7

Factores biofísicos de control de los sistemas lénticos*

\begin{tabular}{|c|c|c|}
\hline \multirow{12}{*}{ 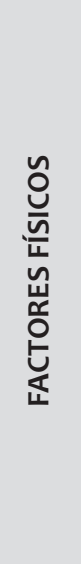 } & \multirow{3}{*}{ GEOLÓGICOS } & Litología \\
\hline & & Estructura \\
\hline & & Hidrogeológicos \\
\hline & \multirow{4}{*}{ GEOMORFOLÓGICOS } & Sistema Morfogenético \\
\hline & & Sistema Morfodinámico \\
\hline & & Modelado \\
\hline & & Formaciones superficiales \\
\hline & CLIMÁTICOS & $\begin{array}{l}\text { Precipitación, evapotrans- } \\
\text { piración }\end{array}$ \\
\hline & \multirow{4}{*}{ HIDROLÓGICOS } & Modo de Alimentación \\
\hline & & Modo de Vaciado \\
\hline & & Hidroperíodo \\
\hline & & Tasa de Renovación \\
\hline \multirow{9}{*}{ 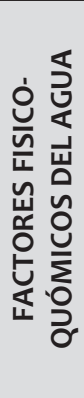 } & MINERALIZACIÓN DEL AGUA & Conductividad y salinidad \\
\hline & TIPOS DE SALES DOMINANTES & \\
\hline & ESTRATIFICACIÓN VERTICAL & \\
\hline & OXÍGENO Y SULFIDRICO DISUELTO & \\
\hline & CONCENTRACIÓN NUTRIENTES INORGÁNICOS & \\
\hline & MATERIA ORGÁNICA & \\
\hline & pH Y RESERVA ALCALINA & \\
\hline & COLMATACIÓN & \\
\hline & TRANSPARENCIA DEL AGUA & \\
\hline \multirow{10}{*}{ 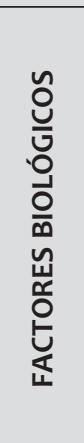 } & MACRÓFITOS & \\
\hline & FITOPLANCTON & \\
\hline & CLOROFILA PLANCTONICA & \\
\hline & FITOBENTOS & \\
\hline & BACTERIAS FOTOSINTÉTICAS DEL AZUFRE & \\
\hline & INVERTEBRADOS PLANCTONICOS Y BENTÓNICOS & \\
\hline & PECES & \\
\hline & OTROS VERTEBRADOS & \\
\hline & PRODUCCIÓN PRIMARIA & \\
\hline & ESTRUCTURA Y FUNCIÓN COMUNIDAD RIBEREÑA & \\
\hline
\end{tabular}

* Fuente: Camacho et al., 2009.

Documentación Administrativa 
Los problemas de conservación a que se enfrentan los humedales están sintéticamente recogidos en Camacho (2008). Éstos son:

- Extracción del agua directamente del humedal para el riego de los cultivos en las zonas agrícolas adyacentes.

- Alteración de los regímenes hídricos sobre todo por sustracción de agua debido a la extensión desmesurada del regadío, aunque también por la demanda para usos residenciales y turísticos. A veces también puede producirse una alteración por exceso.

- Eutrofización (enriquecimiento del agua en nutrientes).

- Contaminación de las aguas por fuentes puntuales o difusas (plaguicidas, herbicidas, metales pesados, o por aportes de microorganismos patógenos asociados a la contaminación por aguas fecales).

- Falta de coordinación para la gestión, asociada al complicado entramado de competencias: confederaciones hidrográficas, CCAA o administración local.

- Falta de consideración de las necesidades hídricas en la planificación hidrológica.

Otros problemas más indirectos son la desecación y el drenaje (sobre todo en el pasado), alteraciones morfológicas, deposición de desechos sólidos (vertidos incontrolados), aislamiento (falta de conectividad), presiones por ocupación del territorio (propio o adyacente), actividades recreativas y explotación de bienes (caza, pesca, turismo), introducción de especies alóctonas, zona de paso de vehículos y personas y uso ganadero. Entre las medidas más específicas para este grupo de sistemas ecológicos se encuentra el completar un Inventario Español de Zonas Húmedas y seguir aplicando el Convenio Ramsar (humedales de Importancia Internacional).

En lo que concierne a los sistemas lóticos (ríos), se estima que la red hidrográfica en su conjunto tiene una longitud de $75.000 \mathrm{~km}$, existiendo unas 1.200 grandes presas lo que supone que España sea uno de los países con mayor grado de regulación hídrica a nivel mundial, siendo además el que posee mayor número de presas por habitante del mundo (Sánchez y Martínez, 2008). Las aguas subterráneas (acuíferos) cubren un tercio de todo el territorio peninsular e insular, las cuales son fundamentales como fuente de alimentación para muchos ríos y zonas húmedas. La caracterización de los ríos y sus riberas depende de la cuenca vertiente y de los factores hidrológicos y geomorfológicos que derivan de ella, los cuales condicionan los tipos de hábitats y comunidades que se desarrollan en el río. El funcionamiento de todos los tipos de ríos responde a unos mismos principios hidrológicos y geomorfológicos, que determinan su buen estado ecológico (González y García, 2007). Dichos principios hacen referencia a: 
- Presentar una continuidad de flujos de agua, sedimentos, energía, etc, desde la cabecera hasta la desembocadura.

- Conectividad de los hábitats asociados al medio fluvial, tanto dentro del cauce como entre el cauce y las riberas y las llanuras de inundación.

- Mantenimiento de las funciones hidrológicas y ecológicas (almacenamiento de agua, retención de sedimentos, meteorización de la materia orgánica, etc.).

En aplicación de la DMA, el Centro de Estudios y Experimentación de Obras Públicas (CEDEX) ha generado una tipología de 32 tipos de ríos atendiendo a diversos factores biofísicos abióticos y bióticos (tabla 8).

\section{TABLA 8}

Factores biofísicos para la tipología de ríos

\begin{tabular}{|c|c|}
\hline \multirow{8}{*}{ 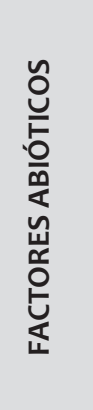 } & Altitud \\
\hline & Latitud y longitud \\
\hline & Oden del río (Strahler) \\
\hline & Pendiente media de la cuenca o pendiente específica \\
\hline & Amplitud térmica anual \\
\hline & Aportación fluvial específica \\
\hline & Porcentaje de meses con caudal nulo \\
\hline & Litología y conductividad base estimada \\
\hline \multirow{6}{*}{ 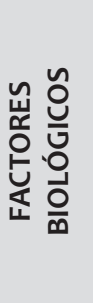 } & Vegetación riparia \\
\hline & Macroinvertebrados bentónicos \\
\hline & Macrófitos \\
\hline & Fitobentos \\
\hline & Peces \\
\hline & Otros vertebrados \\
\hline
\end{tabular}

Fuente: Toro et al., 2009.

Las principales presiones sobre los ríos españoles provienen de la agricultura y del urbanismo mediante la regulación de caudales, la contaminación de las aguas y las canalizaciones y dragados, provocando alteraciones de los hábitats físicos y cambios en la composición y estructura de las comunidades biológicas. Según un estudio de Greenpeace (Barea, 2005), sólo el 11\% de las aguas superficiales y el 16\% de las subterráneas están en condiciones de cumplir los objetivos medioambientales a los que

164 obliga la Directiva Marco del Agua. 
Entre los efectos previsibles debidos al cambio climático cabe mencionar las disminuciones importantes de los aportes hídricos o el aumento de la variabilidad hidrológica en las cuencas atlánticas. Otros efectos serán el cambio de parte de los ecosistemas acuáticos, que pasarán de sistemas permanentes a estacionales (algunos desaparecerán), la reducción de la biodiversidad y la alteración de sus ciclos biogeoquímicos. Los ecosistemas más afectados serán: ambientes endorreicos (La Mancha Húmeda, por ejemplo), lagos, lagunas, ríos y arroyos de alta montaña (1600$2500 \mathrm{~m}$ ), humedales costeros y ambientes dependientes de las aguas subterráneas (VVAA, 2005).

Desde un punto de vista estratégico, el mantenimiento de los ecosistemas lénticos y lóticos en un estado de conservación favorable requiere una adecuada integración en el contenido del Plan Hidrológico Nacional y en el de los Planes Hidrológicos de Cuenca, lo que implica entre otras cosas establecer caudales ambientales y ecológicos para mantener los regímenes hidrológicos y definir características básicas de calidad de las aguas, regulando el sector de la agricultura (sobre todo los regadíos) ya que es la actividad que demanda mayor consumo de recursos hídricos.

\section{El medio Costero y Marino}

Los ecosistemas costeros se consideran los ambientes más productivos del mundo aunque sobre ellos pesa cada vez más una extraordinaria presión por ser las zonas que albergan mayor densidad de población: representan tan sólo entre el 15-20\% de la superficie de la Tierra mientras se estima que más del 50\% de la población humana vive dentro de una franja costera de 200 km (Belfiore, 2005). En España, el 58\% de la población total (unos 23 millones de personas) vive en el 15\% del territorio que suponen nuestras costas, sin olvidar los 40 millones de turistas que se reciben al año (Garcia Varas, 2005).

La costa es un medio especialmente complicado puesto que representa una interfaz entre el medio terrestre y las aguas marinas. España cuenta con casi $8.000 \mathrm{~km}$ de costa: unos $3.100 \mathrm{~km}$ la parte cantábrica y atlántica, $1.900 \mathrm{~km}$ la costa peninsular, casi 1.400 la costa balear y unos $1.500 \mathrm{~km}$ de costa canaria. Los principales factores que conforman la costa son las olas y las corrientes marinas, las lluvias y los aportes de aguas continentales, la temperatura y los vientos, y los factores biológicos (Segovia y Bartolomé, 2002).

La parte rocosa es especialmente extensa y está constituida en su mayor parte por los acantilados marinos, los cuales presentan una gran variabilidad debido a distintos factores biofísicos como son la litología (composición química y características texturales), la estructura (espesor, orientación, grado de alteración), los factores marinos (oleaje, rango mareal, etc.) o la morfodinámica. En los acantilados, las cinturas o bandas de vegetación se sitúan atendiendo a factores marinos básicos como la acción del oleaje y las zonas de influencia de las salpicaduras. En ellos se forman tam- 
bién las cuevas marinas sumergidas o semisumergidas, que suelen ser de mayores dimensiones en los sistemas kársticos, y que se caracterizan por su ambiente hipogeo: oscuridad, elevada humedad relativa, compleja red tridimensional de conductos y galerías o existencia de fauna troglobia entre otras características (López Bedoya y Pérez Alberti, 2009).

La costa arenosa incluye las playas y los sistemas dunares. Las dunas se asocian a costas bajas sedimentarias y se forman por la acción del viento que arrastra la arena desde las playas. Las mayores extensiones de playas se encuentran en Andalucía (sobre todo la zona atlántica), Galicia, Cataluña, Valencia y Canarias. Aunque las dunas pueden clasificarse atendiendo a varios enfoques (por ejemplo, morfológicos o morfo-biológicos), podemos considerar cuatro tipos básicos de ecosistemas dunares: dunas embrionarias o primarias, dunas móviles o secundarias con Ammophila arenaria, depresiones interdunares, secas o húmedas y dunas estabilizadas por bosque, matorral o pastizal. Los factores que forman las dunas son obviamente el suministro arenoso y el control sedimentario que ejerce el mar, el cual depende también del viento y de la orientación de la costa. Así mismo, la vegetación juega un papel fundamental en la nucleación y estabilidad de las dunas (Gracia et al., 2009).

Otros sistemas ecológicos más caracterizados por el medio acuático son los estuarios, las lagunas costeras, las marismas o las grandes calas y bahías. Todos ellos están recogidos en la Directiva Marco del Agua (masas de transición y masas costeras) y en la Directiva 92/43/CEE. No obstante, la selección de los tipos de HIC ligados al medio costero y marino representan una muestra poco satisfactoria, sobre todo frente a los incluidos en el medio terrestre y acuático continental, ya que se encuentran grandes diferencias de escala entre unos y otros, hay evidentes solapamientos espaciales y también definiciones imprecisas (Templado et al., 2009). Aunque para todos los grandes grupos de HIC es necesario llevar a cabo una revisión de los tipos considerados, en el medio marino parece que dicha revisión debe acometerse con mayor profundidad, incluyendo por ejemplo otros ecosistemas ligados a la plataforma continental. Una primera aproximación implicaría tomar en consideración los siguientes tipos de hábitats: montañas submarinas, gases constructores, hábitats pelágicos, desiertos marinos, arrecifes de coral, arrecifes biogénicos de moluscos, poliquetos y crustáceos, prados de algas verdes, concreciones de algas rojas (coralígeno, comunidades de maërl), los bosques de laminarias, los sotobosques de algas pardas, los prados mixtos de algas fotófilas y/o céspedes mixtos de algas, los mantos de algas filamentosas, las charcas intermareales, los hábitats con grandes especies coloniales de hidrozoos, briozoos y tunicados, o los antozoos coloniales (Aguilar et al. 2006; García Varas, 2005).

A lo largo de la costa peninsular española se han definido 12 zonas o subregiones, en función de características geológicas, oceanográficas y biológicas: seis desde las costas catalanas hasta la Zona del Estrecho (Golfo de León, Delta del Ebro, Levante, Promontorio Balear y Mar de Alborán) y seis para la costa atlántica (Golfo de Cádiz, 166 Banco de Galicia, Margen gallego, Margen astur-occidental, Margen astur-oriental y 
Santander-País Vasco). Con respecto a factores de control relevantes, las costas atlánticas tienen rangos de mareas importantes frente al pequeño rango de las costas mediterráneas, lo que se relaciona por ejemplo con la ausencia de marismas o la existencia de albuferas en el Mediterráneo. Son importantes también las características y procedencia de las corrientes marinas lo que influye en la temperatura de las aguas y, por ende, en la composición de las biocenosis marinas. En este sentido, hay que distinguir entre las comunidades ligadas a los fondos (comunidades bentónicas) y las que se desarrollan en la columna de agua (comunidades pelágicas). La zonación de las comunidades bentónicas (gradientes verticales sobre todo) se debe principalmente a tres factores: la iluminación, la sedimentación y el hidrodinamismo. El Mar Mediterráneo presenta baja productividad aunque alberga entre el 4 y el $18 \%$ de todas las especies conocidas y tan sólo representa el $0.83 \%$ de la superficie de los océanos. En conjunto, nuestro medio marino alberga la mayor diversidad biológica en el ámbito europeo.

Los problemas ambientales principales derivan principalmente de la ocupación humana de la costa, lo que implica alteración de la dinámica del litoral (puertos, diques, espigones, etc.) y contaminación de las masas de agua, así como del tráfico marino y de la pesca, la cual hay evidencias de que provoca cambios en las estructuras de los ecosistemas. En el Mediterráneo, por ejemplo, se vierten al año 10 billones de toneladas de aguas residuales industriales y urbanas de las que el $70 \%$ no reciben ningún tipo de tratamiento. Cada año cruzan este mar 220.000 buques de más de 100 toneladas, lo que representa un 30\% de la navegación mercante en el mundo y un 20\% de la navegación petrolera. (SAP BIO, 2006). En cuanto al cambio climático, los principales efectos serían la sequía e inundaciones, cambios en los procesos de erosión del suelo y aportes al litoral, desertización, tormentas, erosión del litoral, aumento de la temperatura y del nivel del mar y corrientes de salinidad. En resumen, entre las presiones más relevantes pueden comentarse las siguientes (García Varas, 2005):

- Pesca: sobreexplotación, utilización de artes de pesca dañinas, redes abandonadas a la deriva o sobre el fondo, alteración de zonas de puesta, capturas accidentales de especies singulares, pérdida de los sistemas de pesca tradicionales.

- Tráfico marítimo: contaminación acústica, contaminación por vertidos tóxicos, introducción de organismos alóctonos por descarga de aguas de lastre.

- Desarrollo litoral: destrucción física de la costa y hábitats contiguos, actividades turísticas descontroladas, desaladoras y descargas submarinas de aguas residuales/emisarios.

- Desarrollo industrial: localización de parques eólicos marinos, plataformas petrolíferas, extracción de arenas y explotaciones mineras, desarrollo intensivo de acuicultura.

- Otras: mareas rojas y proliferaciones de organismos, pérdida de variabilidad genética, contaminación indirecta. 
En lo que se refiere al sistema costero, el marco estratégico de conservación tiene una fuerte componente intersectorial, siendo conveniente tener en cuenta la Recomendación del Consejo y del Parlamento Europeo sobre la Gestión Integrada de las Zonas Costeras (GIZC). En 2008, las Partes Contratantes del Convenio de Barcelona procedieron a la firma del Protocolo relativo a la Gestión Integrada de las Zonas Costeras del Mediterráneo. En su artículo 10 se incluyen las medidas para ecosistemas costeros concretos como son los humedales y estuarios, las dunas o los hábitats marinos. Por otra parte, hay que seguir la aplicación de la Directiva Marco del Agua con respecto a las masas de agua de transición (estuarios) y a las masas costeras. Además, habrá que tener en cuenta la reciente Directiva 2008/56/CE (Directiva Marco sobre la estrategia marina), que tiene como objetivo adoptar las medidas necesarias para lograr o mantener un buen estado medioambiental del medio marino a más tardar en el año 2020. Otros marcos estratégicos internacionales no comunitarios son el Plan de Acción para el Mediterráneo y el Convenio OSPAR, sobre la protección del medio marítimo del Nordeste Atlántico.

\section{BIBLIOGRAFÍA}

Agencia Europea de Medio Ambiente (AEMA). 2008. Tipología de bosques europeos. Categorías y tipos para informes y políticas de gestión forestal sostenible. MARM. 111 pp.

Aguilar, R.; Pasror, X., y M.J. DE Pablo. 2006. Hábitats en peligro. Propuesta de protección de OCEANA. OCEANA y Fundación Biodiversidad.

Alcaraz-Segura, D., Paruelo, J.M.; Oyonarte, C.; Piquer, M., y Cabello, J. 2004. Tipos funcionales de ecosistemas de la Península Ibérica. Implicaciones para el cambio global y la conservación de la biodiversidad. Ecosistemas, 13 (2).

Arco Aguilar, M.J. 1989. El origen de la flora canaria. Quercus, 41:14-21.

Barea, J. (coord.). 2005. Agua. La calidad de las aguas en España. Un estudio por cuencas. GREENPEACE.

Belfiore, S. 2004. Indicadores para la gestión integrada y el desarrollo sostenible de las zonas costeras: iniciativas recientes a nivel regional. En: El Manejo Costero en México. Rivera Arriaga, E., G. J. Villalobos, I. Azuz Adeath, y F. Rosado May (eds.), 2004. Universidad Autónoma de Campeche, SEMARNAT, CETYS-Universidad, Universidad de Quintana Roo. 654 pp.

Bertrán Yanes, E., y Dóniz Páez, J. 2009. 8320 Campos de lava y excavaciones naturales. En: VV.AA., Bases ecológicas preliminares para la conservación de los tipos de hábitat de interés comunitario en España. Dirección General de Medio Natural y Política Forestal, Ministerio de Medio Ambiente, y Medio Rural y Marino. Madrid.

Blanco, E. 2002. Flora. En: B. Asensio (Coord.). La Naturaleza de España: 180-189. Ministerio de Medio Ambiente. Madrid, $381 \mathrm{pp}$.

Blanco, E., y Simón, J.C. 1994. Géneros de plantas vasculares que constituyen endemismos en la Península Ibérica e Islas Baleares. Bol. R. Soc. Esp. Hist. Nat. (Sec. 168 Biol.), 91(1-4): 5-13. 
Camacho, A. 2008. La gestión de los humedales en la política de aguas en España. Panel científico-técnico de seguimiento de la política de aguas. Fundación Nueva Cultura del Agua.

Camacho, A., Borja, C., Valero-Garcés, B., Sahuquillo, M., Soria, J. M., Rico, E., De La Hera, A., García De Domingo, A., Chicote, A. \& Gosálvez, R. U., 2009. 31 Aguas continentales retenidas. Ecosistemas leníticos. En: VV.AA., Bases ecológicas preliminares para la conservación de los tipos de hábitat de interés comunitario en España. Dirección General de Medio Natural y Política Forestal, Ministerio de Medio Ambiente, y Medio Rural y Marino. Madrid. 394 pp.

Carpintero, O. 2005. El metabolismo de la economía española. Recursos naturales y huella ecológica (1955-2000). Economía VS Naturaleza. Fundación César Manrique. Madrid, 636 pp.

Costa Tenorio, M., Morla Juaristi, H., y Sainz Ollero, H. (eds.). 1997. Los bosques ibéricos. Planeta. Barcelona. 572 pp.

Devillers, P., y Devillers-Terschuren, J. 1996. A classification of Palaeartic habitats. Nature and environment, 78. Council of Europe. 194 pp.

García Varas, J.L. (coord.). 2005. Conservando nuestros paraísos marinos. Propuesta de Red Representativa de Áreas Marinas Protegidas en España. WWF/ADENA.

Gómez SAL, A. 2007. Componentes del valor del paisaje mediterráneo y el flujo de servicios de los ecosistemas. Ecosistemas, 16 (3): 97-108.

González del Tánago, M., y García de Jalón, D. 2007. Restauración de ríos. Guía metodológica para la elaboración de proyectos. Ministerio de Medio Ambiente. 318 pp.

Gracia Prieto, F. J., Hernández, L., Hernández, A. I., Flor, G., Gómez, M. Á. \& Sanjaume, E., 2009. 2 Dunas marítimas y continentales. En: VV.AA., Bases ecológicas preliminares para la conservación de los tipos de hábitat de interés comunitario en España. Dirección General de Medio Natural y Política Forestal, Ministerio de Medio Ambiente, y Medio Rural y Marino. Madrid. 106 pp.

Ibáñez, J.J., y García-Álvarez, A. 2002. Diversidad: biodiversidad edáfica y geodiversidad. Edafología, Vol. 9 (3): 329-385.

López Bedoya, J., y Pérez Alberti, A. 2009. 1320 Acantilados con vegetación de las costas atlánticas y bálticas. En: VV.AA., Bases ecológicas preliminares para la conservación de los tipos de hábitat de interés comunitario en España. Dirección General de Medio Natural y Política Forestal, Ministerio de Medio Ambiente, y Medio Rural y Marino. Madrid.

Médail, F. 2009. Los hotspots de biodiversidad, una herramienta para la conservación de la flora mediterránea. Conservación Vegetal, 13: 23-25.

Moreno Saiz, J.C.; Martínez Torres, R., y Tapia, F. 2003. Análisis del estado de conservación de la flora española. En: Bañares, A., Blanca, G., Güemes, J., Moreno, J.C. \& Ortiz, S. (eds.). Atlas y Libro Rojo de la Flora Vascular Amenazada de España. Dirección General de Conservación de la Naturaleza. Madrid, 1072 pp.

Moreno, J.C. (Coord.) 2009. Lista Roja 2008 de la flora vascular española. Dirección General de Medio Natural y Política Forestal (Ministerio de Medio Ambiente, y Medio Rural y Marino), Sociedad Española de Biología de la Conservación de Plantas y Organismo Autónomo de Parques Nacionales. Madrid, 86 pp. 
Naredo, J.M. 2006. Raíces económicas del deterioro ecológico y social. Más allá de los dogmas. Siglo XXI. Madrid. 271 pp.

Noss, R. 1990. Indicators for Monitoring Biodiversity: A Hierarchical Approach. Conservation Biology, Vol. 4, n. ${ }^{\circ}$ : 355-364.

Orella, J.C.; Simón, J.C.; Vaquero, J. Cuadrado, A. Matilla, B. Garzo, M.A., y Sánchez, E. 1998. La Lista nacional de Lugares de la Directiva hábitats 92/43 CEE. Metodología y proceso de evaluación. Ecología, 12: 3-65.

Parra, F., y Naredo, J.M. 2002. Situación diferencial de los recursos naturales españoles. Economía VS Naturaleza. Fundación César Manrique. Madrid. 337 pp.

Ruiz De La Torre, J. 1990. Distribución y características de las masas forestales españolas. Ecología, fuera de serie, 1: 11-30.

Ruiz De La Torre, J. 2002. Vegetación forestal española. En: F.D. Pineda, J.M. de Miguel, M.A. Casado y J. Montalvo (Coord.). La Diversidad Biológica de España: 65-79. Prentice Hall. Madrid.

San Miguel, A; Roig, S., y Canellas, I. 2004. Fruticeticultura. Gestión de arbustedos y matorrales. En: Montero, G. y Serrada, R. (Eds) Compendio de Selvicultura Aplicada en España. DGCONA. Madrid.

Sánchez Navarro, R., y Martínez Fernández, J. 2008. Los caudales ambientales: Diagnóstico y perspectiva. Panel científico-técnico de seguimiento de la política de aguas. Fundación Nueva Cultura del Agua.

Sap Bio (Plan de Acción Estratégico para la Conservación de la Diversidad Biológica en la Región Mediterránea), 2006. Informe Nacional Español. Ministerio de Medio Ambiente.

Segovia, E., y Bartolomé, J. (Coord.). 2002. El litoral mediterráneo: importancia, diagnóstico y conservación. WWF/ADENA.

Simón Zarzoso, J.C. 1994. La flora vascular española: Diversidad y conservación. Ecología, 8:203-225.

Strasburguer. 1986. Tratado de Botánica. Editorial Marín. Barcelona. 1098 pp.

Suárez Cardona, F.; Sainz Ollero, H.; Santos Martínez, T., y González Bernáldez, F. 1991. Las estepas ibéricas. Ministerio de Obras Públicas y Transportes. Madrid. 160 pp.

TEMPLADO, J.; Guallart, J.; Capa, M., y Luque, A. 2009. 1170 Arrecifes. En: VV.AA., Bases ecológicas preliminares para la conservación de los tipos de hábitat de interés comunitario en España. Dirección General de Medio Natural y Política Forestal, Ministerio de Medio Ambiente, y Medio Rural y Marino. Madrid.

Terradas, J. 2001. Ecología de la vegetación. Ediciones Omega. Barcelona. 703 pp.

Toro, M.; Robles, S.; Tejero, I.; Prat, N.; Solá, C., y Beltrán, D. 2009. 32 Aguas continentales corrientes-sistemas lóticos. En: VV.AA., Bases ecológicas preliminares para la conservación de los tipos de hábitat de interés comunitario en España. Dirección General de Medio Natural y Política Forestal, Ministerio de Medio Ambiente, y Medio Rural y Marino. Madrid.

Valladares, F. (eds.). 2004. Ecología del bosque mediterráneo en un mundo cambiante. Naturaleza y Parques Nacionales. Serie Técnica. Organismo Autónomo de Parques Nacionales. 587 pp.

VV.AA., 2005. Evaluación preliminar de los efectos del cambio climático en España. 170 Ministerio de Medio Ambiente. Madrid, 822 pp. 